\title{
Capacity of ZAECA in Conducting Research and Guidance to Fight Corruption in Zanzibar
}

\author{
Shambuli Salum Meru' ${ }^{1}$ and Prof. Nsubuga Haroonah ${ }^{2}$ \\ ${ }^{1}$ Head of section of research and prevention, Zanzibar Anti-Corruption and Economic Crimes Authority \\ ${ }^{2}$ DVC-Academic, Zanzibar University
}

\begin{abstract}
The main focus of this study is to examine the capacity of ZAECA in conducting research and guidance to fight corruption in Zanzibar. The study employed a descriptive case study research design. The target population of this study was employees in the Ministry of Public Services and Good Governance and its Commissions and Authorities including; ZAECA, Commission for Good Governance, Commission of Ethics in Public Services, Commission for Human Rights, Institute of Public Administration, Control Auditor General (CAG) and the office of Director of Public Prosecution (DPP). Judgmental sampling and simple random sampling techniques were used to select a sample size of 85 respondents. The study found that ZAECA does not have sufficient powers to effectively carry out its mandate and the respondents rated a moderate capacity in conducting research and guidance to fight corruption, human resources and independence. The study concludes that ZAECA does not have sufficient powers to effectively carry out its mandate and that ZAECA is not free from undue influence. Finally, the study recommended that the government should ensure that ZAECA is independent and autonomous by clearly delinking it from political influence.
\end{abstract}

Key words: ZAECA, Corruption, Anti-corruption Agency

\section{Introduction}

Corruption is 'the abuse of entrusted power for private gain'. According to the report by Organization for Economic Co-Operation and Development (OECD) (2008) that; the recent international treaties against corruption require their member states to establish specialized bodies dedicated to fighting and preventing corruption. The United Nations Convention against Corruption requires the existence of two types of anticorruption institutions namely; a body or bodies that prevent corruption and a body, bodies or persons specialized in combating corruption through law enforcement.

Both the prevention of corruption and combating corruption through law enforcement involves a large number of multidisciplinary functions. When considering establishing or strengthening anti-corruption bodies, countries need to take into consideration the full range of anti-corruption functions, including the Policy development, research, monitoring and co-ordination. Although its effects on democratic institutions and economic and social development have long been apparent, the fight against corruption has only recently been placed high on the international policy agenda. Today, many international organizations are addressing the global and multi-faceted challenge of fighting corruption (OECD, 2008). Corruption undermines trust in democratic institutions and weakens the accountability of political leadership. Moreover, it enables organized crime groups to use corruption to commit other serious crimes, such as trafficking in drugs and human beings.

In Zanzibar, until late 2011, corruption was only investigated by the police. This changed in 2012, with the establishment of the Zanzibar Anti-Corruption and Economic Crimes Authority (ZAECA). The ZAECA is an independent and autonomous agency and has adequate capacities for fulfilling its mandate to cover the prevention and educational role in corruption-related matters by means of, inter alia, monitoring of public 
entities, advising the public and the private sector, and awareness-raising. The authority is also mandated to investigate alleged corruption cases and possess enhanced investigatory powers to arrest, to enter into premises or vessels, search and detain suspects and seize property as well as to summon witnesses and documents (Institute of Development Research and Development Policy (IEE), 2014).

Moreover, the Zanzibar anti-corruption Act makes provisions on conflicts arising from overlapping investigation mandates: In case there is a dispute between ZAECA and the police about an investigation, the Director of Public Prosecutions (DPP) has the power to order the police officer to investigate that allegation. This means in return that, the ZAECA is only a secondary investigation force ranging behind the police and also has to report the results of each investigation to the DPP.

\section{Problem Statement}

Corruption is pervasive throughout Tanzanian society and is a serious problem across all sectors of the economy. The most affected sectors are government procurement, land administration, taxation, and customs. Petty corruption in dealings with traffic, customs, and immigration officers deters investment. Corruption is criminalized under the Zanzibar Anti-Corruption and Economic Crimes Act No. 1 of 2012, which covers attempted corruption, extortion, passive and active bribery, money laundering and bribery of a foreign official. A range of legislation covers other corruption offenses, but anti-corruption laws are applied inconsistently and are poorly enforced.

corruption cases delivered by ZAECA statistics from 2013 to 2019 support that there has been increasing number of cases of corruption that mainly have been associated with illegal use of public assets, employment cheating, office misuse for self-interest, taking and giving bribes, drug abuse and bribery in office tendering. It is very important to note that, there were; 15 cases in 2013,57 cases in 2014,77 cases in 2015, 119 cases in 2016, 187 cases in 2017, 209 cases in 2018 and 230 cases in 2019 (ZAECA, 2020).

\section{Theoretical literature review}

The study governed by Public choice theory and Grand Theories of Change for Fighting Corruption. Public choice theories developed by Geoffrey Brennan and James Buchanan (1985) who argue that the rules that regulate the activities of individuals within a society matter and are a major determinant of how individuals and organizations behave. The theory regards corruption as post-constitutional opportunism designed to generate benefits for individuals or groups at the expense of the rest of society.

Grand Theories of Change for Fighting Corruption Jasper (2012) argues that in seeking to understand "what works and why," particularly for complex governance and anticorruption interventions, one needs to disentangle distinct elements such as implementation failure, flawed design, and external constraints.

\section{Empirical Literature Review}

It has been identified that a lot of studies related to retirement packages on the lives of the public sector have been conducted by many researchers from Tanzania and outside. The followings are some of them.

Wangui, (2014) conducted a study on, Impediments to Effective Investigation and Prosecution of Corruption Cases in Kenya: The Case of the Ethics and Anti-Corruption Commission (EACC) on Kenya. The study found that, the legal framework, court rulings and slow judicial process have presented serious challenges to effective execution of EACC mandate

Adebusuyi (2019) conducted a research on: Qualitative Study on Patterns, Experiences and Manifestations of Corruption in Nigeria; The case of United Nations Office on Drugs and Crime (UNODC) Abuja, Nigeria. Adebusuyi found out that; corruption could actually be eradicated from the country through processes of sustained value re-orientation (via establishment of relevant educational curricula and by means of religious teaching), public enlightenment and holistic improvement in the conditions of existence in the country.

Mohamed (2018) conducted a study on corruption in Kenya. He observed that; Corruption is often associated with abuse of entrusted power and embezzlement of resources where a bribe is a major factor in 
exchange for preferential treatment and where there is corruption there is always bad governance. Like many other countries in the world, Kenya's economy has been crippled by corruption hence making Kenyans live in abject poverty.

Kaluya (2018), conducted a research on Corruption in Uganda: A Comparative Study of Citizens' and Public Officials' Perceptions. The study analyzed secondary data consisting of 12,000 citizens and 670 public officials within 80 districts in Uganda on their perception of corruption and the degree of corruption forms in the Ugandan public institutions. The data were using factorial analysis of variance and factorial multivariate analysis of variance (MANOVA) statistical procedures. This study finds that corruption is engendered by an unholy alliance between citizens desperate to access services and public officials eager to exact a price on services they are obliged to freely provide.

Mazigo (2014) conducted a study on the Causes of Corruption in Construction Public Procurement in Tanzania: A Case of Manyara Region. The study employed a case study design where by 140 respondents were purposively selected among experts in the construction profession. These included consultants, architects, quantity surveyors, engineers and contractors. Simple random sampling was used to select public officials from Manyara region. The data were collected by using questionnaires, interviews and documentary review. Both qualitative and quantitative data were analyzed using SPSS software. On his study he found that; the main causes of corruption are lack of transparency, bureaucracy, lack of legal framework, behaviour aspects of some unfaithful procurements officials, discretion, lack of accountability and even budgeting problems.

\section{Methodology}

A descriptive research design was used in this study because of its appropriateness in establishing relationships between variables and facilitating the collection of information for determining the population parameters. This study conducted at ministry of constitution, legal affair, public service and good governance which is located in Urban West Region at Vuga Street.

The study population of this study was 3500 employees of the Ministry of Public Services and Good Governance and its Commissions and Authorities including; ZAECA, Commission for Good Governance, Commission of Ethics in Public Services, Commission for Human Rights, Institute of Public Administration, Control Auditor General (CAG) and the office of Director of Public Prosecution (DPP).

Purposive and simple random techniques were used to select 85 sample size which consist Directors, head of departments and sections and other experts in ZAECA

The study used questionnaire as a tools of data collection from the respondents. Quantitative data was analysed using descriptive, mean scores, frequencies and percentages. A computer package (IBM SPSS Statistics 23) was used to aid in processing the data

\section{Findings of the study}

\subsection{Demographic of the respondents.}

The respondents were drawn from different levels among ZAECA staff such as directors, heads of departments, investigation officers, legal officers, heads of sections and the normal staff. All respondents' characteristics such as education level, sex, income and experience were included. However, the study achieved $95.8 \%$ of the response rate from both questionnaire and interview conducted as shown in table 1 hereunder.

Table 1 Demographic of the respondents

\begin{tabular}{|l|l|l|l|}
\hline Variable & Category & Frequency & Percentage (\%) \\
\hline & Male & 41 & 48.2 \\
Gender & Female & 44 & 51.8 \\
\hline
\end{tabular}




\begin{tabular}{|l|l|l|l|}
\hline \multirow{3}{*}{ Education level } & Certificate level & 13 & 15.3 \\
& Diploma level & 29 & 34.1 \\
& Bachelor degree & 35 & 41.2 \\
& Master and above & 8 & 9.4 \\
\hline \multirow{3}{*}{ Working experiences } & 0-5 years & 38 & 44.7 \\
& 6-10 years & 37 & 43.5 \\
& $11-15$ years & 10 & 11.8 \\
\hline \multirow{3}{*}{ Age category } & $18-28$ & 12 & \\
& $29-39$ & 51 & 14.1 \\
& $40-50$ & 12 & 60.0 \\
& $51+$ above & 10 & 14.1 \\
& & & \\
\hline
\end{tabular}

The gender of respondents was analyzed in order to determine their sex distribution in the organization. The study found that majority of respondents were female Though the female respondents outweighed male respondents, opinions of both genders on the contribution of 'ZAECA' on prevention of corruption was considered necessary.

Most of employees in ZAECA are educated this implies that most of employees in ZAECA were satisfactory educated and therefore, they were expected to perform their duties diligently. This is related with their working experiences where by respondents have enough experiences which implies that they have knowledge on corruption practices in Zanzibar.

Finally the study comprises the age category of the respondents and found that, ZAECA workforce comprises of youthful and middle aged employees out of senior employees.

\subsection{Capacity of ZAECA in Conducting Research and Guidance to Fight Corruption in Zanzibar}

The study seeks to determine the capacity of ZAECA in conducting research and guidance to fight corruption in Zanzibar. All 85 respondents sought to respond with this objective that focused on main four areas which are; capacity in conducting research and guidance to fight corruption, human resources capacity, ZAECA independence and limitations in prosecutorial powers.

\subsubsection{Capacity in Conducting Research and Guidance to Fight Corruption}

This part aimed at realizing the capacity of ZAECA in conducting research and guidance to effectively combating with corruption. . The respondents were asked to rate their agreement with statements in regard to human resources, ICT infrastructures, information resources, institutional structure and physical resources capacity and the results were as follow:

Table 3Capacity in Conducting Research and Guidance to Fight Corruption

\begin{tabular}{|l|r|r|}
\hline Variables & $\mathrm{N}$ & \multicolumn{1}{c|}{ Mean } \\
\hline Financial Capacity & 85 & 3.5529 \\
\hline ICT Infrastructures' Capacity & 85 & 4.4118 \\
\hline Information Resources' Capacity & 85 & 3.5059 \\
\hline Physical Resources' Capacity & 85 & 4.0824 \\
\hline Institutional Structure Capacity & 85 & 3.8353 \\
\hline Total & & 19.3883 \\
\hline
\end{tabular}

Source: Research findings, 2020

The study in table 3 revealed that, respondents rated moderate capacity in financial resource $(\mathrm{n}=85, \mathrm{M}=$ 3.5529), information resources $(n=85, M=3$. 3.5059) and the institutional structure $(n=85, M=3.8353)$. While respondents rated low capacity in ICT infrastructures $(n=85, M=4.4118)$ and physical resources ( $n$ $=85, \mathrm{M}=4.0824)$. 
The findings imply that; financially ZAECA is not healthy enough to satisfy the need of conducting research and guidance. This is probably due to insufficient budget allocated to research and guidance, poor source of funding the projects or least prioritization in research and guidance. ZAECA not well established yet in term of ICT infrastructural resources to enable effective attainment of research and guidance toward fighting the corruption. The information capacity is not maintained enough to support effective research and guidance in fighting against corruption.

\subsubsection{Human Resources Capacity}

The respondents were asked to rate their agreement with statements in regard human resources capacity constraints at ZAECA and its effect on investigation and prosecution of corruption cases the finding summarised in table 4 below.

Table 4 Human Resource capacity

\begin{tabular}{|l|r|r|}
\hline Statement & $\mathrm{N}$ & \multicolumn{1}{l|}{ Mean } \\
\hline ZAECA has adequate HR to investigate corruption & 85 & 2.6235 \\
\hline ZAECA has shortage of forensic investigators & 85 & 3.6353 \\
\hline ZAECA not adequately trained to handle technological gadgets & 85 & 3.7882 \\
\hline ZAECA expanded its services country wide & 85 & 2.7176 \\
\hline ZAECA has enough HR capacity in research and guidance & 85 & 2.0471 \\
\hline ZAECA staff ratio to population and corruption level is low & 85 & 3.7647 \\
\hline shortage of forensic experts has slowed ZAECA in investigating cases & 85 & 3.9059 \\
\hline ZAECA lacks in regional presence due to inadequate specialized skills & 85 & 3.7294 \\
\hline ZAECA staff has adequate capacity for investigation and prosecution of & 85 & 1.9647 \\
\hline corruption cases & 85 & \\
\hline
\end{tabular}

Source: Field Data, 2020

Table 4 shows that, respondents strongly disagreed with the statements that ZAECA staff has adequate capacity for investigation and prosecution of corruption cases $(n=85, M=1.96)$; The respondents also disagreed with the statements that ZAECA has adequate HR to investigate corruption $(n=85, M=2.62)$; ZAECA expanded its services country wide $(\mathrm{n}=85, \mathrm{M}=2.71)$; and ZAECA has enough HR capacity in research and guidance $(\mathrm{n}=85, \mathrm{M}=2.04)$.

However, respondents neither agreed nor disagreed with the statements that ZAECA has shortage of forensic investigators $(n=85, M=3.63)$; ZAECA lacks in regional presence due to inadequate specialized skills ( $\mathrm{n}=85, \mathrm{M}=3.72)$; ZAECA staff ratio to population and corruption level is low $(\mathrm{n}=85, \mathrm{M}=3.76)$; shortage of forensic experts has slowed ZAECA in investigating cases $(n=85, M=3.90)$; and ZAECA not adequately trained to handle technological gadgets $(n=85, M=3.78)$.

The results show that, there is no adequate financial resources dedicated to training specialists in investigation and ZAECA has no adequate human resource to investigate corruption.

\subsubsection{ZAECA independence}

The respondents were asked rate their level of agreement with a number of statements in regard to ZAECA independence. The results are summarised in table 5

Table 5 ZAECA Independence

\begin{tabular}{|l|r|l|}
\hline Statement & $\mathrm{N}$ & \multicolumn{1}{l|}{ Mean } \\
\hline ZAECA Act provides full autonomy in conducting research & 85 & 3.0000 \\
\hline ZAECA is free from any undue influence & 85 & 2.8235 \\
\hline safeguards are in place for appointment of qualified staff of integrity & 85 & 2.8471 \\
\hline ZAECA has sufficient powers to carry out its mandate & 85 & 2.9059 \\
\hline Government is supportive of ZAECA to maintain adequate independence & 85 & 3.0000 \\
\hline
\end{tabular}

Source: research findings, 2020 
As presented in Table 5 respondents disagreed with the statements that, ZAECA is free from any undue influence $(n=85, M=2.82)$; safeguards are in place for appointment of qualified staff of integrity $(n=85$, $M=2.84)$; and ZAECA has sufficient powers to effectively carry out its mandate ( $n=85, M=2.90)$.

However, respondents were neutral on the statements that ZAECA Act provides full autonomy in conducting research $(\mathrm{n}=85, \mathrm{M}=3.00)$; and the Government is supportive of ZAECA to maintain adequate independence $(n=85, M=3.00)$. The results show that ZAECA does not have sufficient powers to effectively carry out its mandate and also it is not free from undue influence. Buchanan (1985) argued that the rules that regulate the activities of individuals within a society matter and are a major determinant of how individuals and organizations behave.

\subsubsection{Limitations in Prosecutorial Powers}

Respondents were requested rate their level of agreement with statements in regard to limitations in prosecutorial powers and their effect on effective investigation and prosecution of corruption cases by ZAECA as presented in table 6 here under

Table 6: Limitations in Prosecutorial Powers

\begin{tabular}{|l|c|l|}
\hline Statement & $\mathrm{N}$ & Mean \\
\hline $\begin{array}{l}\text { Recommendation of prosecution by ZAECA to DPP reduces its } \\
\text { effectiveness in combating corruption }\end{array}$ & 85 & 3.1765 \\
\hline Most cases forwarded to DPP are approved for prosecution & 85 & 3.2941 \\
\hline Most suspected corrupt people are convicted in court & 85 & 2.2235 \\
\hline $\begin{array}{l}\text { Outcome of most cases recommended for prosecution is acquittal } \\
\text { Most of cases recommended by DPP for prosecution are closed or returned } \\
\text { for further investigation }\end{array}$ & 85 & 3.0824 \\
\hline The level of prosecution of prosecution cases recommended to DPP is high & 85 & 3.1529 \\
\hline
\end{tabular}

Source: Field Data, 2020

Table 6 shows that, respondents disagreed with the statements that Most suspected corrupt people are convicted in court $(n=85, M=2.22)$. The respondents were however neutral on the statements that Recommendation of prosecution by ZAECA to DPP reduces its effectiveness in combating corruption $(n=85, M=3.17)$; Most cases forwarded to DPP are approved for prosecution $(n=85, M=3.2941)$; Outcome of most cases recommended for prosecution is acquittal( $\mathrm{n}=85, \mathrm{M}=3.0824)$; Most of cases recommended by DPP for prosecution are closed or returned for further investigation $(n=85, M=3.15)$; and thelevel of prosecution of prosecution cases recommended to DPP is high(n=85, M=3.78).

The results show the limitations in prosecutorial powers affect effective investigation and prosecution of corruption cases by ZAECA because most suspected corrupt people are not convicted in court. The challenge is almost common in many developing countries, Mazigo (2014) support this fact in his study on the Causes of Corruption in Construction Public Procurement in Tanzania which concluded that; the main causes of corruption are lack of transparency, bureaucracy, lack of legal framework, behaviour aspects of some unfaithful procurements officials, discretion, lack of accountability and even budgeting problems. Therefore, these are probably the same that, ZAECA as confronted by the said limitations on its prosecutorial powers for corruption cases.

\section{Conclusion}

From the findings of the study, it can be concluded that ZAECA does not have sufficient powers to effectively carry out its mandate and that ZAECA is not free from undue influence. This was confirmed by respondents' disagreement with the statements that ZAECA has sufficient powers to effectively carry out its' mandate $(n=85, M=2.9059)$ and ZAECA is free from any undue influence $(n=85, M=2.8235)$. As to the case of professionalism the respondents disagree with the statement that ZAECA has enough HR capacity in research and guidance $(n=85, M=2.0471)$. Also the respondents disagree with the statement that ZAECA has adequate $\mathrm{HR}$ to investigate corruption $(\mathrm{n}=85, \mathrm{M}=2.6235)$. 


\section{Recommendations}

Based on the findings and conclusions of the study, the following recommendations were made: The Revolutionary Government of Zanzibar should ensure that, there is an effective legal framework for ZAECA to fight against corruption. This should entail a detailed operational framework of the ZAECA to enhance its performance.

Government should also ensure that ZAECA is independent and autonomous by clearly delinking it from political influence. In addition, the government should allocate adequate resources to the ZAECA for it to execute its mandate effectively and independently without undue influence from other quarters.

The ZAECA should build its human resource capacity by attracting competent skills, training and equipping employees with the necessary tools of work. This has not been possible owing to limited budget for ZAECA and lack of allocation for training experts in investigations. Also the legislature should give ZAECA the power to prosecute. Limitation of ZAECA to investigations has resulted to poor performance of the Authority.

\section{References}

1. Adebusuyi I, A. (2019). Qualitative Study on Patterns, Experiences and Manifestations of Corruption in Nigeria: United Nations Office on Drugs and Crime (UNODC) Abuja, Nigeria

2. Babbie, E. (2005). Survey Research Methods (3rd ed.). Belmont: Wodsworth.

3. Kaluya, M.D. (2018) "Corruption in Uganda: A Comparative Study of Citizens' and Public Officials' Perceptions", African Social Science Review: Vol.9: No.1, Article 4.

4. Wangui M.C, (2014) Impediments to Effective Investigation and Prosecution of Corruption Cases in Kenya: The Case of the Ethics and Anticorruption Commission

5. Mazigo, D. (2014)causes of corruption in construction publicprocurement in Tanzania: A case of Manyara Region, Tanzania.

6. Jesper J. (2012) Theories of change in anti-corruption work: A tool for programme design and Evaluation. Anti-Corruption Resource Centre. Finland.

7. Mohamed M, N. (2018) Corruption in Kenya: Degree Thesis BBA-International Business: Financial Management, Nairobi.

8. Organisation of Economic Cooperation and Development (2008). Integrity in Public Procurement, Good Practice from A to Z, Paris, Organisation of Economic Cooperationand Development.

9. Institute of Development Research and Development Policy (IEE), 2014. The Role of AntiCorruption Agencies in the Investigation and Prosecution of Procurement Related Corruption Cases; IEE Working Papers, No. 209. Ruhr University Bochum

10. Zanzibar Anti-Corruption and Economic Crimes Act No. 1 of 2012: Retrieved June 10, 2020 from the World Wide Web: http://www.zaeca.go.tz 